\title{
Derivatives Use In The Partial Hedging Of Currency Risk: A Firm-Specific Approach To Understanding The Exchange Rate Exposure Puzzle
}

Olesya Savchenko, University of Wisconsin Oshkosh, USA

Stephen Makar, University of Wisconsin Oshkosh, USA

\begin{abstract}
This study investigates whether firms with significant foreign exchange rate exposure change their future use of foreign exchange rate derivatives ( $F X D$ s). Unlike prior research, we employ firmspecific accounting data on hedging strategy and currency risk. Our results indicate that firms with high FXDs use relative to their foreign sales have significant exposure to either firm-specific bilateral exchange rates or a broad exchange rate index. Among such firms with significant foreign exchange rate exposure, we find that partial hedgers change their future use of FXDs, consistent with our expectations for firms that monitor the effectiveness of their hedging strategy. These results are timely in light of the increased scrutiny of derivatives use during the current financial crisis, and contribute to our understanding of extant research on returns-based estimates of foreign exchange rate exposure (aka, the exchange rate exposure puzzle).
\end{abstract}

Keywords: Derivatives, Partial Hedging, Exchange Rate Exposure

\section{INTRODUCTION}

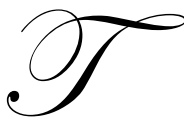

he use of derivatives has come under increased scrutiny by lawmakers, regulators, practitioners, and academics. In the U.S., "many in Congress blame such instruments for exacerbating the financial crisis," and Treasury officials are exploring regulation "to prevent another financial meltdown caused by hidden exposure to derivatives risk" (Scannell, 2009, page B1). At the practitioner level, the use of foreign exchange rate derivatives (FXDs) is being reassessed by firms attempting to effectively manage the dramatic increase in currency risk accompanying the financial crisis (Kirschner et al., 2009). Motivated by such increased scrutiny, academics are investigating the role of derivatives in understanding the surprising lack of empirical evidence of significant returns-based estimates of exchange rate exposure; aka, the "exchange rate exposure puzzle" (e.g. Bartram and Bodnar, 2007).

This study employs a firm-specific approach to refining the analysis of exchange rate exposure, and investigates whether firms with significant exposure (if any) modify their future use of FXDs. To the extent firms monitor the effectiveness of their hedging strategy, we expect firms with significant returns-based estimates of foreign exchange rate exposure will change their future derivatives use accordingly. We shed light on the exchange rate exposure puzzle by taking advantage of firm-specific accounting data on currency risk and hedging strategy, and by examining changes in firms' FXDs use in relation to their past efforts to effectively hedge exchange rate exposure. Such firm-specific data allows us to identify the bilateral exchange rate to which the firm is most exposed, and whether the firm uses a partial hedging strategy; that is, whether it chooses to hedge less than 100 percent of its exposure to changing exchange rates.

Employing this refined approach, we find significant returns-based estimates of exchange rate exposure for firms with high FXDs use relative to foreign sales. Of these firms, however, only partial hedgers modify their future 
FXDs use. Moreover, we provide preliminary evidence that these firms' future use of derivatives is effective in reducing the magnitude of their exposure to changing exchange rates. In sum, the results suggest that partial hedgers with significant exchange rate exposure do monitor the effectiveness of their hedging strategy and adjust future FXDs use accordingly.

The remainder of this paper is organized as follows. Section 2 provides background and develops the two research hypotheses; Section 3 describes the data and methodology used to test the hypotheses; Section 4 presents and discusses the results, and Section 5 concludes the paper.

\section{BACKGROUND AND HYPOTHESES}

Economic theory suggests that firm value is related to changes in exchange rates (e.g. Jorion, 1990). In a recent review of the empirical research on the relationship between market returns and changes in exchange rates, Bartram and Bodnar (2007) describe the surprising lack of evidence of such a relation as the "exchange rate exposure puzzle." This gap in our understanding of exchange rate exposure has been attributed, in part, to the firm's effective use of foreign exchange derivatives (FXDs) in managing currency risk, and to the difficulties in modeling the firm's exchange rate exposure including the use of broad exchange rate indexes, which may not capture the bilateral exchange rate exposure particular to each firm (e.g. Allayannis and Ofek, 2001; Ihrig, 2001). This study addresses these two explanations for the exchange rate exposure puzzle by following a firm-specific approach to estimating and explaining foreign exchange rate exposure.

This study takes advantage of accounting data disclosed in accordance with the Securities and Exchange Commission's (SEC) Financial Reporting Release (FRR) No. 48 (SEC, 1997). Under FRR No. 48, U.S. multinationals provide qualitative data on their currency risk including the identification of the bilateral exchange rate to which they are most exposed, and their use of a partial hedging strategy where less than 100 percent of the firm's exchange rate exposure is hedged. We use such firm-specific data to refine returns-based estimates of exchange rate exposure, and to distinguish firms following a partial hedge strategy in our examination of changes in FXDs use. To the extent firms monitor the effectiveness of their hedging strategy, we expect firms with significant returns-based estimates of exchange rate exposure will change their future use of FXDs accordingly. ${ }^{1}$ In particular, we test the following hypotheses (in null form).

H1: There is no association between monthly market model residual errors and monthly changes in the exchange rate.

H2: There is no association between the change in derivative use and past ineffective use of derivatives.

\section{DATA AND METHOD}

This study employs a firm-specific approach to understanding the exchange rate exposure puzzle, and departs from prior research in two important ways. First, we use FRR No. 48 disclosures to identify both the bilateral exchange rate to which the firm is most exposed and whether the firm uses a partial hedging strategy. ${ }^{2}$ Second, we distinguish partial hedgers in examining whether firms with significant exchange rate exposure (if any) modify their future use of foreign exchange rate derivatives (FXDs). Extant survey evidence documents the prevalence of partial hedging strategies (e.g. Bodnar et al., 1998; Borsum and Odegaard, 2005; Naylor and Greenwood, 2008). In addition, recent research suggests that U.S. multinationals' (MNCs) risk management practices and the pricing of exchange rate exposure are affected by the Financial Accounting Standards Board (FASB) promulgations (e.g. Lins et al., 2008; Gao and Senteney, 2009; Zhang, 2009). In light of such evidence, we focus our study on the 2001-2006 period after the adoption of Statement of Financial Accounting Standard (SFAS) No. 133 (FASB, 1998). ${ }^{3}$

As detailed in Panel A of Table 1, we selected non-financial U.S. MNCs with ex ante exposure to changing exchange rates as proxied by the foreign sales ratio. ${ }^{4}$ Excluding firms with insufficient currency risk and FXDs use disclosures, as well as firms lacking monthly returns and annual data in Compustat, the initial sample is reduced to 131 firms. Of these initial sample firms, 89 firms report that they are primarily exposed to changes in the U.S. dollar 
in relation to either the British Pound or a Euro-zone currency. Like the trade-weighted exchange rate index prevalent in prior studies of exchange rate exposure, we weight the changes in such firm-specific bilateral exchange rates by the ratio of the firm's sales in the corresponding geographic region to its total sales. ${ }^{5}$ As seen in Panel B, the final sample of 89 firms represents a variety of non-financial industry sectors.

Tests of hypothesis one use pooled time-series cross-sectional estimates of equation (1) over the 2001-2003 period, for the full sample and for three portfolios representing low, medium, and high relative FXDs users (portfolios are formed using the mean ratio of FXDs to foreign sales, for the period of interest). This market model approach to estimating exchange rate exposure is prevalent in extant research (e.g. Adler and Dumas, 1984; Zhang, 2009). In addition to the foreign-sales weighted principal currencies from FRR No. 48 disclosures (ERFIRM), we use the broad trade-weighted exchange rate index from the International Monetary Fund's International Financial Statistics (ERIMF) to promote comparisons with prior research.

$\mathrm{R}_{\mathrm{it}}=\alpha+\lambda_{1} \mathrm{MKT}_{\mathrm{t}}+\lambda_{2} \mathrm{FXI}_{\mathrm{it}}+\varepsilon_{\mathrm{it}}$

where:

$\mathrm{R}_{i t}$ is the monthly return on security $\mathrm{i}$ for month $\mathrm{t}$;

$\mathrm{MKT}_{\mathrm{t}}$ is the monthly return of the CRSP value-weighted market index for month $\mathrm{t}$;

$\mathrm{FXI}_{\mathrm{it}}$ is the percentage change in either the sales-weighted bilateral exchange rate to which firm $\mathrm{i}$ is most exposed in period t (ERFIRM, per FRR No. 44 hand-gathered data), or the nominal trade-weighted exchange rate index (ERIMF, per International Financial Statistics); both FXI variables are stated in direct form (i.e. U.S. dollar value of one unit of foreign currency).

To the extent sample firms are exposed to changes in exchange rates (using either ERFIRM or ERIMF), the estimated coefficient on the FXI variable will be statistically significant.

Building on the returns-based estimates of exchange rate exposure from equation (1), tests of hypothesis two examine whether firms with significant exposure (if any) modify their future FXDs use. In particular, equation (2) is estimated for the full sample and the partial hedge sub-sample, over the 2004-2006 period.

$\Delta \mathrm{FXDFS}_{\mathrm{ip}}=\alpha+\beta_{1} \mathrm{EDUM}_{\mathrm{ip}}+\beta_{2-4} \Delta \mathrm{CONTROLS}+\varepsilon_{\mathrm{ip}}$,

where:

$\triangle \mathrm{FXDFS}_{\mathrm{ip}}$ is the annual change in foreign exchange derivatives in period $\mathrm{p}$ for firm $\mathrm{i}$ (as measured by the notional value scaled by foreign sales);

EDUM $_{i p}$ equals 1 for firm i in a FXDFS portfolio with statistically significant exchange rate exposure for period $\mathrm{p}$ from equation (1), else 0 ; or $\mathrm{PH} * \mathrm{EDUM}$ for firms with statistically significant equation (1) exposure that identify themselves as partial hedgers;

$\triangle$ CONTROLS $_{\text {ip }}$ are the annual change in other determinants of FXDs use from extant research, as proxied by SIZE (firm size, as measured by the natural log of total assets, to control for scale economies in derivatives use), LEV (leverage, as measured by the ratio of total debt to total assets, to control for financial distress costs), and RD (R\&D, as measured by the ratio of $R \& D$ to total sales, to control for under-investment costs).

To the extent firms with significant exchange rate exposure modify their future FXDs use, the estimated coefficient on the EDUM (or PH*EDUM) variable will be statistically significant for the full sample (or the partial hedge sub-sample). 


\section{RESULTS}

Table 2 presents descriptive statistics for both the full sample and the FXDFS portfolios (formed using the mean ratio of FXDs to foreign sales), over the 2001-2006 sample period as well as the 2001-2003 and 2004-2006 periods used in estimating equation (1) and equation (2), respectively. In Panel A, the two equation (1) FXI variables (ERFIRM and ERIMF) exhibit similar levels of variability across the sample period. However, in contrast to the broad ERIIMF variable, the standard deviations of the firm-specific ERFIRM variable are much larger within each period. Thus, it is important to distinguish these two variables in equation (1) estimates. In Panel B, the equation (2) dependent variable (FXDFS) has a positive mean in all three periods, indicating that sample firms increased their FXDs use relative to foreign sales across the 2001-2006 period.

\subsection{Primary analysis}

Table 3 details the tests of hypothesis one for 2001-2003. Panel A presents OLS estimates of equation (1) using the firm-specific bilateral exchange rates from FRR No. 48 disclosures (ERFIRM), and Panel B provides the OLS estimation results for equation (1) using the International Monetary Fund's trade-weighted exchange rate index (ERIMF). ${ }^{6}$ Looking first to the full sample results in the last column, the estimated coefficient on the FXI variable is significant (at the .10 level or better) using either the firm-specific exchange rates (in Panel A) or the broad exchange rate index (in Panel B). Thus, hypothesis one is supported. Within this full sample, we consistently identify firms in FXDFS portfolio 3 as having significant returns-based estimates of exchange rate exposure.

The Table 3 results indicate that it is the sub-sample of firms using the largest amount of FXDs relative to foreign sales (i.e. FXDFS portfolio 3) that faces significant exposure to changing exchange rates. Moreover, the positive FXI coefficient indicates that, on average, a decline (increase) in the value of the U.S. dollar (vis-à-vis either the currency to which the firm is most exposed, or the exchange rate index) is associated with an increase (decrease) in firm value. ${ }^{7}$ Finally, comparing the magnitude of the FXI coefficients, sample firms face more exposure to the broad exchange rate index (ERIMF).

Table 4 presents tests of hypothesis two using equation (2), which examine whether firms with significant exchange rate exposure in 2001-2003 change their FXDs use in 2004-2006. To the extent firms monitor the effectiveness of their hedging strategy, we expect firms with significant returns-based estimates of exchange rate exposure (i.e. firms in FXDFS portfolio 3, per Table 3 results) will modify their future FXDs use. As detailed in Panel A, the full sample results do not support these expectations. In particular, model 4 depicts the equation (2) OLS estimation results, which indicate that the variable of interest (EDUM) is not statistically significant (at the .10 level). Estimation results for models 1-3 are provided for completeness. ${ }^{8}$ Although the Panel A full sample results indicate that firms with significant exchange rate exposure do not modify their FXDs use, it is important to distinguish partial hedgers in examining the implications of ineffective hedging strategy for future derivatives use.

In contrast to the Panel A full sample results, the Panel B evidence for partial hedgers supports hypothesis two. As seen in model 4, the equation (2) results indicate that partial hedgers with significant exchange rate exposure (i.e. $\mathrm{PH}^{*} \mathrm{EDUM}=1$ ) do modify their future use of FXDs (significant at the .05 level). Moreover, the positive sign of the $\mathrm{PH} * \mathrm{EDUM}$ coefficient suggests that partial hedgers that are ineffective in managing their currency risk in 2001-2003 increase their FXDs use in 2004-2006. These full model results are robust to the exclusion of all controls and the inclusion of either the SIZE control or both the SIZE and the LEV controls, as seen in models 1-3. All together, the results suggest that firms with significant exchange rate exposure that follow a partial hedge strategy do monitor hedge effectiveness, and adjust their future derivatives use accordingly.

\subsection{Additional analysis}

The Table 4 evidence, which supports hypothesis two, pertains only to the subset of partial hedgers facing significant exchange rate exposure (i.e. partial hedgers in FXDFS portfolio 3, per Table 3 hypothesis one results for 2001-2003). Moreover, although such results suggest that these partial hedgers do monitor hedge effectiveness and adjust their 2004-2006 derivatives use, tests of hypothesis two are not designed to examine whether their FXDs use in 2004-2006 is effective in reducing the firm's exposure to changing exchange rates. To provide preliminary 
evidence in these areas, we extend our analysis beyond the formal tests of hypothesis two using a two-step OLS regression approach for the 2004-2006 period of interest.

In the first step, time-series estimates of equation (3) provide returns-based estimates of exchange rate exposure using the broad exchange rate index (ERIMF). The absolute value of these time-series estimates then is used in the second step, as the dependent variable in cross-sectional estimates of equation (4). ${ }^{9}$

$\mathrm{R}_{\mathrm{it}}=\alpha+\lambda_{1} \mathrm{MKT}_{\mathrm{t}}+\lambda_{2} \mathrm{ERIMF}_{\mathrm{it}}+\varepsilon_{\mathrm{it}}$

where:

$\mathrm{R}_{i t}$ is the monthly return on security i for month $\mathrm{t}$;

$\mathrm{MKT}_{\mathrm{t}}$ is the monthly return of the CRSP value-weighted market index for month $\mathrm{t}$;

$\mathrm{ERIMF}_{\text {it }}$ is the percentage change in the nominal trade-weighted exchange rate index, per the International Monetary Fund's International Financial Statistics.

Abs $\lambda_{2 \mathrm{i}}=\alpha+\gamma_{1} \mathrm{PH}^{*}$ MFXDFS $_{\mathrm{i}}+\gamma_{2}$ MSIZE $_{\mathrm{i}}+\gamma_{3} \mathrm{MLEV}_{\mathrm{i}}+\gamma_{4} \mathrm{MRD}_{\mathrm{i}}+\varepsilon_{\mathrm{i}}$

where:

Abs $\lambda_{2 \mathrm{i}}$ is the absolute value of estimated ERIMF coefficient from equation (3), for firm i;

$\mathrm{PH}^{*}$ MFXDFS $_{\mathrm{i}}$ is the mean value of the relative amount of FXDs for firm i multiplied by an indicator variable (equals 1 if the firm identifies itself as a partial hedger, and 0 otherwise);

MSIZE $_{\mathrm{i}}$ is the natural log of the mean value of the market value of equity for firm i;

$\mathrm{MLEV}_{\mathrm{i}}$ is the mean value of the ratio of total debt to total assets for firm i;

$M R D_{i}$ is the mean value of the ratio of $R \& D$ to total sales for firm $i$.

To the extent partial hedgers effectively use FXDs to reduce the magnitude of their exchange rate exposure, the coefficient on the PH*MFXDFS variable will be significant and negative. In addition to estimating these two equations for the sub-sample of interest (i.e. FXDFS portfolio 3, in Table 4 Panel B hypothesis two results), we provide full sample results to consider the effectiveness of FXDs use for all partial hedgers.

Table 5 details the OLS estimates of equation (4) based on the absolute value of the exchange rate exposure estimates from equation (3). As seen in Panel A, the full sample results are not statistically significant (at the .10 level). In contrast, the coefficient on the PH*MFXDFS variable (significant at the .10 level) in Panel B is consistent with our expectations for partial hedgers with significant exchange rate exposure (i.e. FXDFS portfolio 3). Together with our primary results in Tables 3 and 4, the evidence suggests that partial hedgers monitor the effectiveness of their hedge strategy and adjust their future FXDs use in a way that reduces the magnitude of their exposure to changing exchange rates.

\section{CONCLUSION}

This study investigates whether U.S. multinationals (MNCs) with significant foreign exchange rate exposure change their future use of foreign exchange rate derivatives (FXDs). Unlike prior research, we take advantage of data on the firm's hedging strategy to identify partial hedgers, and the firm's currency risk to improve returns-based estimates of exchange rate exposure. To the extent MNCs monitor the effectiveness of their hedging strategy, we expect firms with significant exchange rate exposure will change their future use of FXDs accordingly. 
Consistent with these expectations, we provide results that support both of the formal hypotheses. Tests of hypothesis one indicate that sample firms with high FXDs use relative to their foreign sales face significant exposure to either the firm-specific bilateral exchange rates or the broad exchange rate index. Moreover, such results indicate that, on average, a decline (increase) in the value of the U.S. dollar is associated with an increase (decline) in firm value. Building on these results, tests of hypothesis two support our expectations, but only for firms that follow a strategy of hedging less than 100 percent of their exchange rate exposure (i.e. partial hedgers). Finally, we provide preliminary evidence that partial hedgers facing significant exposure modify their future FXDs use in a way that is effective in managing currency risk. All together, the results suggest that partial hedgers with significant exchange rate exposure do monitor the effectiveness of their hedging strategy, and adjust their future derivatives use accordingly.

The results presented in this study are timely given the increased scrutiny of derivatives use, and shed light on the exchange rate exposure puzzle. Extant survey research indicates that most firms do not fully hedge their exposure to exchange rate changes (e.g. Bodnar et al., 1998). We provide evidence that such partial hedgers monitor hedge effectiveness and adjust their derivatives use in a way that is prudent, consistent with recent research (e.g. Zhang, 2009). Future research can shed further light on the exchange rate exposure puzzle and the debate over prudent derivatives use by considering the speculative nature of partial hedging strategies. By following such a strategy of not hedging 100 percent of their exposure to changes in exchange rates, partial hedgers may choose to take on increased currency risk with the intent of earning the increased returns commensurate with such risk.

Panel A: Description of data

Table 1. Sample Selection

Sample of firms incorporated in U.S with at least $10 \%$ of foreign sales ratio in 2001

No. of firms

Sample with available hand gathered data on currency risk and derivatives use

Sample with available Compustat data - initial sample

Sample with primary exposure to British Pound or Euro-zone currency in 2001- final sample ${ }^{\mathrm{a}}$

Panel B: Industry distribution ( 2 digit Standard Industrial Classification code) in 2001

$22 \mathrm{XX}$

$23 X X$

$24 X X$

$25 \mathrm{XX}$

$26 \mathrm{XX}$

$28 \mathrm{XX}$

29XX

$30 \mathrm{XX}$

$31 \mathrm{XX}$

$33 \mathrm{XX}$

$34 \mathrm{XX}$

$35 \mathrm{XX}$

$36 \mathrm{XX}$

$37 \mathrm{XX}$

$38 X X$

Food and kindred products

Textile mill products

Apparel and other textile products

Lumber and wood products

Furniture and fixtures

Paper and allied products

Chemicals and allied products

No. of firms

Petroleum and coal products

Rubber and miscellaneous plastic products

Leather and leather products

Primary metals industries

Fabricated metal products

Industrial machinery and equipment

Electronic and other electric equipment

3

Transportation equipment

Instruments and related products

Miscellaneous manufactured industries

Final sample

1

1

1

${ }^{a}$ The U.S. firms in the final sample are those that identify either the US\$/British Pound (21 firms) or a US\$/Euro-zone currency (68 firms) as the exchange rate to which they are primarily exposed, and represent 68 percent of the 131 firms in the initial sample. The next two most common principal exchange rates for the initial sample of 131 firms are the US\$/Canadian\$ (14 firms) and the US\$/Japanese Yen (14 firms). 
Table 2. Descriptive Statistics

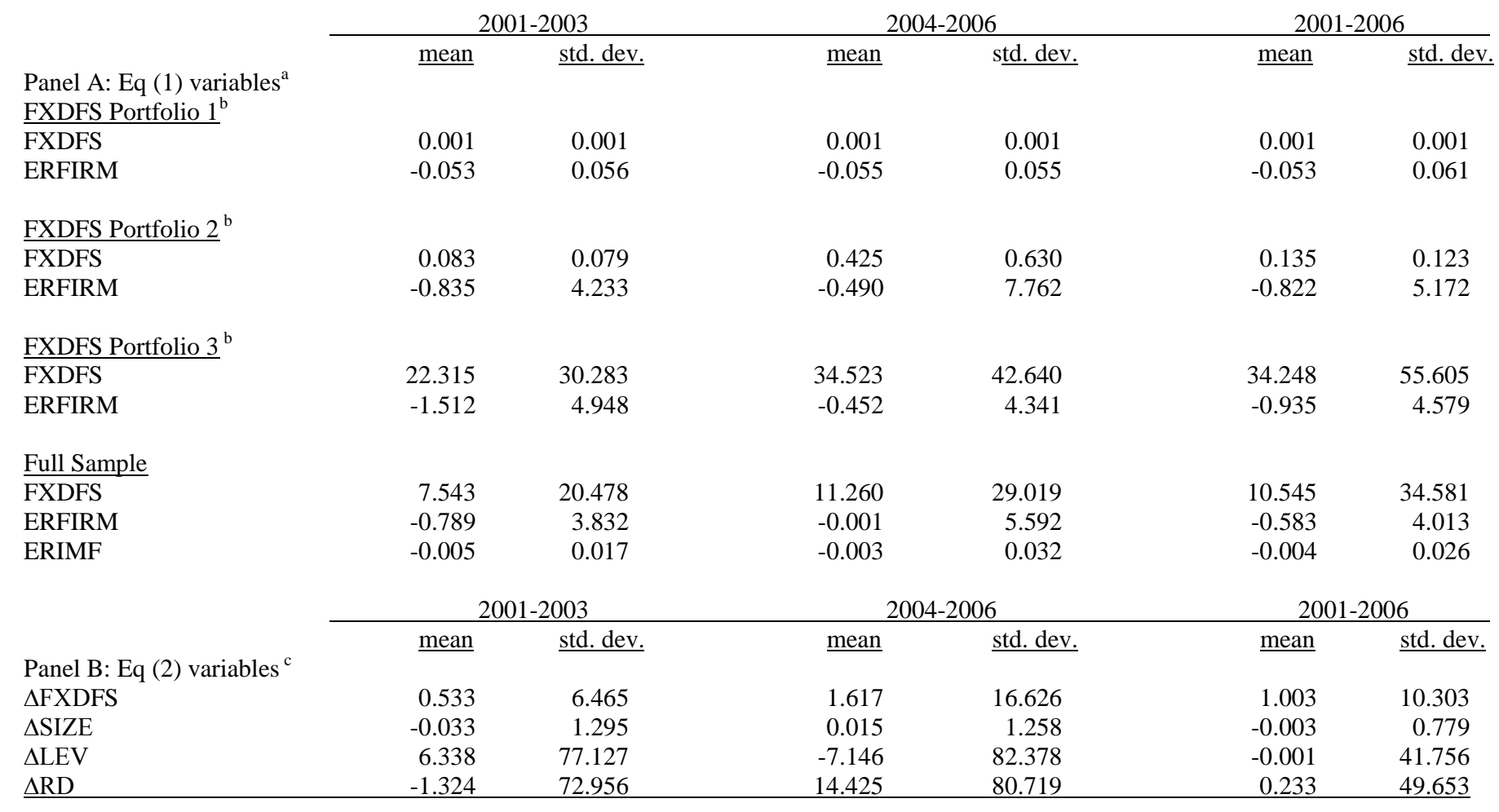

${ }^{a}$ Equation (1) identifies ineffective hedgers (hypothesis 1) based on the monthly FX market model over the 2001-2003 period, using either the firm-specific bilateral exchange rate (ERFIRM) or the IMF trade-weighted foreign exchange index (ERIMF), for the full sample as well as for each of the three portfolios representing low-medium-high users of foreign exchange derivatives relative to foreign sales (FXDFS). The 2004-2006 and 2001-2006 periods are provided for comparison purposes.

${ }^{b}$ Portfolios are formed using the time-series mean FXDFS for each company. The distribution of the 89 sample firms in 2001, across the FXDFS portfolios, is: 29, 30 , and 30.

${ }^{c}$ Equation (2) examines the annual changes in scaled foreign exchange derivatives ( $\triangle$ FXDFS) for the full sample over the $2004-2006$ period (hypothesis 2), in relation to the ineffective use of derivatives (per equation (1) tests of hypothesis 1$)$, the log of the market value of equity ( $\Delta$ SIZE), the ratio of total debt to total assets ( $\Delta$ LEV), and the ratio of R\&D to total sales $(\Delta R D)$. The 2001-2003 and 2001-2006 periods are provided for comparison purposes. 
Table 3. Tests Of Hypothesis One (2001-2003) ${ }^{\mathrm{A}}$

\begin{tabular}{|c|c|c|c|c|}
\hline Variable symbol & $\begin{array}{l}\text { FXDFS } \\
\text { Portfolio } 1^{\mathrm{b}}\end{array}$ & $\begin{array}{c}\text { FXDFS } \\
\text { Portfolio } 2^{\mathrm{b}}\end{array}$ & $\begin{array}{l}\text { FXDFS } \\
\text { Portfolio } 3^{b}\end{array}$ & $\begin{array}{c}\text { Full } \\
\text { Sample }\end{array}$ \\
\hline \multicolumn{5}{|l|}{ Panel A: ERFIRM } \\
\hline $\mathrm{R}^{2}$ & 0.147 & 0.117 & 0.199 & 0.150 \\
\hline F-value & $88.96 * * *$ & $54.38 * * *$ & $111.09 * * *$ & $243.95 * * *$ \\
\hline Intercept (t-value) & $0.021(4.50)^{* * *}$ & $0.020(4.11) * * *$ & $0.020(4.75)^{* * *}$ & $0.020(7.63)^{* * *}$ \\
\hline MKT (t-value) & $1.171(13.32)^{* * *}$ & $0.949(10.43)^{* * *}$ & $1.107(14.85)^{* * *}$ & $1.084(22.05)^{* * *}$ \\
\hline FXI (t-value) & $0.005(0.88)$ & $-0.001(-0.13)$ & $0.001(1.68)^{*}$ & $0.001(1.65)^{*}$ \\
\hline \multicolumn{5}{|l|}{ Panel B: ERIMF } \\
\hline $\mathrm{R}^{2}$ & 0.104 & 0.136 & 0.166 & 0.127 \\
\hline F-value & $86.74 * * *$ & $78.38 * * *$ & $127.44 * * *$ & $274.66 * * *$ \\
\hline Intercept (t-value) & $0.023(4.84)^{* * *}$ & $0.022(4.73)^{* * *}$ & $0.021(5.42)^{* * *}$ & $0.022(8.46)^{* * *}$ \\
\hline MKT (t-value) & $1.154(13.12)^{* * *}$ & $1.077(12.52)^{* * * *}$ & $1.123(15.96)^{* * *}$ & $1.123(23.42)^{* * *}$ \\
\hline FXI (t-value) & $0.237(0.88)$ & $0.428(1.60)$ & $0.579(2.70)^{* * *}$ & $0.405(2.76) * * *$ \\
\hline
\end{tabular}

${ }^{a}$ Tests of hypothesis one use pooled time-series cross-sectional estimates of equation (1) for the full sample or for each of the FXDFS portfolio sub-samples over the 2001-2003 period, where a significant coefficient on the FXI variable is consistent with ineffective FXDs hedging. Equation (1) is the monthly FX market model: R $=\alpha+\lambda_{\mathrm{o}}$ MKT $+\lambda_{1}$ FXI $+\varepsilon$, where $R$ is the firm's return, $M K T$ is the CRSP value weighted market return, and $F X I$ is the percentage change in either the firm-specific sales-weighted bilateral exchange rate (ERFIRM in Panel A) or the trade-weighted U.S. dollar exchange rate index (ERIMF in Panel B). Both FXI variables are expressed as the U.S. dollar value of one unit of foreign currency.

${ }^{b}$ Portfolios are formed using the time-series mean FXDFS for each company, where FXDFS is the currency derivative notional value scaled by foreign sales. The distribution of the 89 sample firms in 2001 across the FXDFS portfolios is: 29, 30, and 30.

*Significant at the 10 two-sided level

**Significant at the 05 two-sided level

***Significant at the .01 two-sided level 
Table 4. Tests Of Hypothesis Two (2004-2006)

\begin{tabular}{|c|c|c|c|c|}
\hline Variable symbol & Model 1 & Model 2 & Model 3 & Model 4 \\
\hline \multicolumn{5}{|l|}{ Panel A: FXDFS Portfolio $3^{\text {a }}$} \\
\hline $\operatorname{Adj} R^{2}$ & 0.008 & 0.004 & 0.001 & -0.002 \\
\hline F-value & 2.31 & 1.31 & 1.05 & 0.91 \\
\hline Intercept (t-value) & $0.284(0.17)$ & $0.292(0.865)$ & $0.209(0.12)$ & $-0.047(-0.03)$ \\
\hline EDUM (t-value) & $4.470(1.52)$ & $4.532(1.54)$ & $4.655(1.57)$ & $4.802(1.62)$ \\
\hline SIZE (t-value) & - & $-0.650(-0.56)$ & $-0.997(-0.80)$ & $-0.977(-0.78)$ \\
\hline LEV (t-value) & - & - & $-0.013(-0.73)$ & $0.001(0.04)$ \\
\hline RD (t-value) & - & - & - & $0.022(0.72)$ \\
\hline \multicolumn{5}{|c|}{ Panel B: Partial Hedgers in FXDFS Portfolio $3^{\mathbf{b}}$} \\
\hline$\overline{\operatorname{Adj} R^{2}}$ & 0.018 & 0.014 & 0.011 & 0.010 \\
\hline F-value & $3.87 * *$ & 2.09 & 1.57 & 1.41 \\
\hline Intercept (t-value) & $0.723(0.49)$ & $0.741(0.50)$ & $0.685(0.46)$ & $0.321(0.21)$ \\
\hline PH*EDUM (t-value) & $7.996(1.97)^{* *}$ & $8.084(1.98)^{* *}$ & $8.200(2.01)^{* *}$ & $8.858(2.14)^{* *}$ \\
\hline SIZE (t-value) & - & $-0.667(-0.58)$ & $-1.009(-0.81)$ & $-0.987(-0.79)$ \\
\hline LEV (t-value) & - & - & $-0.013(-0.72)$ & $0.006(0.22)$ \\
\hline $\mathrm{RD}$ (t-value) & - & - & - & $0.029(0.96)$ \\
\hline
\end{tabular}

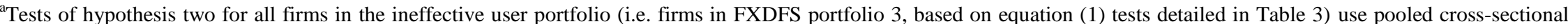
estimates of equation (2), as depicted in model 4, for the full sample over the 2004-2006 period, where a significant coefficient on the EDUM variable is consistent with ineffective FXD users changing their future FXD use. Equation (2) is: $\triangle \mathrm{FXDFS}=\alpha+\beta_{1}$ EDUM $+\beta_{2} \Delta \mathrm{SIZE}+\beta_{3} \Delta \mathrm{LEV}+\beta_{4} \Delta \mathrm{RD}+\varepsilon$, where $\Delta F X D F S=$ annual change in FXD use, as measured by notional values scaled by foreign sales; $E D U M=1$ for firms in an ineffective user portfolio, else $0 ; \triangle S I Z E=$ annual change in the natural log of the market value of equity; $\triangle L E V=$ annual change in the ratio of total debt to total assets, to control for the costs of financial distress; and $\triangle R D=$ annual change in the ratio of R\&D to total sales, to control for under-investment costs.

${ }^{\mathrm{b}}$ Additional tests of hypothesis two for partial hedgers in the ineffective user portfolio (i.e. firms in FXDFS portfolio 3 that identify themselves as partial hedgers) use pooled crosssectional estimates of equation (2), as depicted in model 4, for the full sample over the 2004-2006 period, where a significant coefficient on the PH*EDUM variable is consistent with ineffective FXD users that identify themselves as partial hedgers changing their future FXD use. Equation (2) is: $\Delta$ FXDFS $=\alpha+\beta_{1}$ PH*EDUM $+\beta_{2} \Delta$ SIZE $+\beta_{3} \Delta$ LEV + $\beta_{4} \triangle \mathrm{RD}+\varepsilon$, where $\triangle F X D F S=$ annual change in FXD use, as measured by notional values scaled by foreign sales; $P H * E D U M=1$ for partial hedger firms in ineffective user portfolio, else $0 ; \triangle S I Z E=$ natural log of the market value of equity; $\triangle L E V=$ annual change in the ratio of total debt to total assets, to control for the costs of financial distress; and $\triangle R D=$ annual change in the ratio of $R \& D$ to total sales, to control for under-investment costs.

*Significant at the .10 two-sided level

** Significant at the .05 two-sided level

$* * *$ Significant at the .01 two-sided level 
Table 5. Additional Tests: Fxe Determinants (2004-2006) ${ }^{\text {A }}$

\begin{tabular}{|c|c|c|c|c|}
\hline Variable symbol & Model 1 & Model 2 & Model 3 & Model 4 \\
\hline \multicolumn{5}{|c|}{ Panel A: Partial Hedgers in Full Sample ${ }^{\mathbf{a}}$} \\
\hline $\operatorname{Adj~} R^{2}$ & 0.014 & 0.009 & -0.013 & -0.027 \\
\hline F-value & 2.06 & 1.03 & 0.68 & 0.52 \\
\hline Intercept (t-value) & $0.299(7.61)^{* * *}$ & $0.337(1.66)$ & $0.337(1.64)$ & $0.278(0.89)$ \\
\hline PH*MFXDFS (t-value) & $-0.003(-1.43)$ & $-0.003(-1.39)$ & $-0.003(-1.38)$ & $-0.003(-1.25)$ \\
\hline MSIZE (t-value) & - & $-0.008(-0.19)$ & $-0.008(-0.19)$ & $-0.002(-0.04)$ \\
\hline MLEV (t-value) & - & - & $-0.001(-0.02)$ & $-0.001(-0.05)$ \\
\hline MRD (t-value) & - & - & - & $0.001(0.25)$ \\
\hline \multicolumn{5}{|c|}{ Panel B: Partial Hedgers in FXDFS Portfolio $3^{\mathbf{b}}$} \\
\hline$\overline{\operatorname{Adj} R^{2}}$ & 0.003 & 0.014 & 0.021 & 0.044 \\
\hline F-value & 1.65 & 1.16 & $2.65^{* *}$ & $3.71 * * *$ \\
\hline Intercept (t-value) & $0.418(13.70)^{* * *}$ & $0.510(4.36)^{* * *}$ & $0.660(5.00)^{* * *}$ & $0.882(5.65)^{* * *}$ \\
\hline PH*MFXDFS (t-value) & $-0.004(-1.28)$ & $-0.004(-1.26)$ & $-0.004(-1.28)$ & $-0.005(-1.69)^{*}$ \\
\hline MSIZE (t-value) & - & $-0.019(-0.82)$ & $-0.046(-2.36)^{* *}$ & $-0.082(-2.86)^{* *}$ \\
\hline MLEV (t-value) & - & - & $-0.002(-1.80)^{*}$ & $-0.002(-2.85)^{* *}$ \\
\hline MRD (t-value) & - & - & - & $-0.001(-2.58) * *$ \\
\hline
\end{tabular}

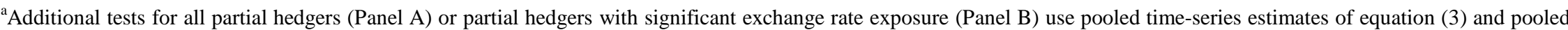
cross-sectional estimates of equation (4) for the full sample (Panel A) or the FXDFS Portfolio 3 sub-sample (Panel B) over the 2004-2006 period. A significant and negative coefficient on the equation (4) PH*MFXDFS variable is consistent with effective FXDs use by partial hedgers in the Panel A (Panel B) full sample (ineffective user portfolio, as detailed in Table 3). Equation (3) is the monthly market model: $\mathrm{R}=\alpha+\lambda_{0}$ MKT $+\lambda_{1}$ ERIMF $+\varepsilon$, where $R$ is the firm's return, $M K T$ is the CRSP value weighted market return, and ERIMF is the percentage change in the trade-weighted U.S. dollar exchange rate index. Equation (4) is Abs $\lambda_{1}=\alpha+\gamma_{1} \mathrm{PH} * \mathrm{MFXDFS}+\gamma_{2} \mathrm{MSIZE}+\gamma_{3} \mathrm{MLEV}+\gamma_{4} \mathrm{MRD}+\varepsilon$, where Abs $\lambda_{1 \mathrm{i}}$ is the absolute value of estimated ERIMF coefficient from equation (3), $P H^{*} M F X D F S$ is the mean value of the annual changes in the relative amount of FXDs multiplied by an indicator variable (equals 1 if the firm identifies itself as a partial hedger, and 0 otherwise), MSIZE is the natural log of the mean value of the market value of equity, $M L E V$ is the mean value of the ratio of total debt to total assets, and $M R D$ is the mean value of the ratio of R\&D to total sales.

${ }^{\mathrm{b}} \mathrm{FXD}$ users with significant exchange rate exposure per results detailed in Table 3, where portfolios are formed using the time-series mean FXDFS for each company, and FXDFS is the currency derivative notional value scaled by foreign sales. As shown in Table 3, the ineffective FXD users are sample firms in FXDFS portfolio 3.

*Significant at the .10 two-sided level

**Significant at the .05 two-sided level

***Significant at the .01 two-sided level 


\section{ENDNOTES}

${ }^{1}$ Our approach to identifying ineffective derivative users is similar to Zhang (2009), who distinguishes ineffective hedgers as those firms with increased levels of returns-based estimates of foreign exchange rate exposure after starting a derivatives program.

${ }^{2}$ Makar and Huffman (2008) take a similar approach to improving returns-based estimates of exchange rate exposure for U.K. multinationals. They find a higher incidence of exchange rate exposure using firm-specific bilateral exchange rates compared to the exposure estimates using a broad exchange rate index.

${ }^{3}$ Zhang (2009), for example, reports that ineffective hedgers modify their derivatives use after the adoption of SFAS No. 133. Our 2001-2006 sample period also allows us to consider the sensitivity of hypothesis two tests to the monitoring of hedge effectiveness under SFAS No. 133. Under SFAS No. 133, firms can use hedge accounting to reduce the earnings fluctuations from mark-to-market adjustments on derivative hedges. To use hedge accounting, however, firms must evaluate whether the hedge is "highly effective."

${ }^{4}$ Our sample selection criteria is guided by extant evidence that non-financial multinationals are major users of currency derivatives, and that such firms' exposure to changing exchange rates is an increasing function of the ratio of foreign sales to total sales (e.g. Jorion, 1990; Bodnar et al., 1998).

${ }^{5}$ In light of the dominance of such European currencies for our sample firms and the need to weight each firmspecific currency by the firm's sales in that geographic region, we focus our analysis on these 89 firms. Across the 2001-2006 sample period, 15-22 firms identify the British Pound as their primary currency. Not all these firms, however, disclose their sales level for the U.K. separate from Europe. In such cases, the ratio of the firm's European sales to its total sales is used to weight the changes in the US\$/British Pound exchange rate. The primary results are robust to the exclusion of these firms.

${ }^{6}$ Model diagnostics suggest that estimates of equation (1) and equation (2) are not hindered by departures from OLS assumptions. Such diagnostics include the Shapiro-Wilk test for non-normality, the White test for heteroscedasticity, and diagnostics from the INFLUENCE option in SAS to evaluate the presence of outliers.

${ }^{7}$ Although theory suggests a relationship between fluctuations in exchange rates and changes in firm value, the predicted causation is bi-directional (e.g. Rim and Mohidin, 2005). Thus, for our Table 3 results, the decline (increase) in the value of the U.S. dollar may lead to or result from the increase (decrease) in firm value.

${ }^{8}$ Although not reported in Table 4 Panel A (Panel B), such full sample (partial hedge sub-sample) evidence is robust to identifying firms who are required to monitor hedge effectiveness under SFAS No. 133. As footnoted in Section 2, firms using SFAS No. 133 hedge accounting are required to evaluate hedge effectiveness, with both retroactive and prospective evaluations required at least every three months.

${ }^{9}$ The specification of equation (3) is identical to equation (1). However, equation (3) is estimated for each firm and for the broad exchange rate index only (i.e. ERIMF). In contrast, equation (1) is estimated across firms using either the bilateral exchange rate or the exchange rate index. In our two step OLS tests, time-series estimates of equation (3) are needed for equation (4) tests. We focus on the ERMIF variable in such additional tests, in light of the equation (1) results detailed in Table 3.

\section{AUTHOR INFORMATION}

Olesya Savchenko received her MBA from the University of Wisconsin Oshkosh in 2009, and is currently applying for admission to a PhD program. While at UW Oshkosh, she earned the University's Graduate Studies Outstanding Research Award.

Stephen Makar is a Professor of Accounting in the College of Business. He has 40 peer-reviewed articles and paper presentations. Among the publications he found most rewarding were those from faculty-student collaborative 
research projects, including the current article with Ms. Savchenko. The coauthors would like to thank the Faculty Development Office at UW Oshkosh for its support of their collaborative work.

\section{REFERENCES}

1. Adler, M. and B. Dumas. 1984. Exposure to Currency Risk: Definition and Measurement. Financial Management. 13, 41-50.

2. Allayannis, G. and E. Ofek. 2001. Exchange Rate Exposure, Hedging, and the Use of Foreign Currency Derivatives. Journal of International Money and Finance. 20, 273-296.

3. Bartram, S. 2008. What Lies Beneath: Foreign Exchange Rate Exposure, Hedging and Cash Flows. Journal of Banking and Finance. 32, 1508-1521.

4. Bartam, S. and G. Bodnar. 2007. The Exchange Rate Exposure Puzzle. Managerial Finance. 33, 642-666.

5. Bodnar, G., G. Hayt and R. Marston. 1998. 1998 Wharton Survey of Financial Risk Management by U.S. Non-financial Firms. Financial Management. 27, 70-91.

6. Borsum, O. and B. Odegaard. 2005. Currency Hedging in Norwegian Firms. Economic Bulletin, 76, 133145.

7. Financial Accounting Standards Board. 1998. Statement of Financial Accounting Standard No. 133. Accounting for Derivative Instruments and Hedging Activities. Author: Stamford, CT.

8. Gao, G. and D. Senteney. 2009. The Market Reaction Associated with SFAS No. 8 and SFAS No. 52: Did Investors Recognize Differential Economic Content of Translation Gains and Losses? Journal of Applied Business Research. 25, 63-75.

9. Ihrig, J. 2001. International Finance Discussion Paper No. 709. Exchange Rate Exposure of Multinationals: Focusing on Exchange Rate Issues. Board of Governors of the Federal Reserve System: Washington, DC.

10. Jorion, P. 1990. The Exchange-rate Exposure of U.S. Multinationals. Journal of Business. 63, 331-345.

11. Kirschner, L., E. Holbrook and J. Wade. 2009. The Power of the Dollar. Risk Management. 56, 76-80.

12. Lins, K., H. Servaes and A. Tamayo. 2008. Does Derivative Accounting Affect Risk Management? Unpublished Working Paper. University of Utah.

13. Makar, S. and S. Huffman. 2008. U.K. Multinationals' Effective Use of Financial Currency Derivatives. Journal of International Financial Management and Accounting. 19, 219-235.

14. Naylor, M. and R. Greenwood. 2008. The Characteristics of Foreign Exchange Hedging: A Comparative Analysis. Journal of Asian-Pacific Finance. 9, 124-142.

15. Rim, H. and R. Mohidin. 2005. On the Dynamic Relationship between Exchange Rates and Industry Stock Prices: Some Empirical Evidence from Malaysia. Journal of Applied Business Research. 21, 49-60.

16. Scannell, K. 2009. Big Companies Go to Washington to Fight Regulation of Fancy Derivatives. The Wall Street Journal. July 10, p. B1.

17. Securities and Exchange Commission. 1997. Financial Reporting Release No. 48. Disclosure of Accounting Policies for Derivative Financial Instruments and Derivative Commodity Instruments and Disclosure of Quantitative and Qualitative Information about Market Risk Inherent in Derivative Financial Instruments, Other Financial Instruments, and Derivative Commodity Instruments. Author: Washington, DC.

18. Williamson, R. 2001. Exchange Rate Exposure and Competition. Journal of Financial Economics. 59, 441475 .

19. Zhang, H. 2009. Effect of Derivative Accounting Rules on Corporate Risk-management Behavior. Journal of Accounting and Economics. 47, 244-264. 